\title{
WORK ABILITY INDEX AND MUSCULOSKELETAL DISORDERS IN WORKERS AT TRAKIA UNIVERSITY - STARA ZAGORA
}

\author{
G. Sandeva ${ }^{1}$, V. Tsvetkova ${ }^{2}$, G. Prakova ${ }^{2 *}$ \\ ${ }^{1}$ Department of Hygiene, Epidemiology and Infectious Diseases, Medical Faculty, Trakia University, \\ Stara Zagora, Bulgaria \\ ${ }^{2}$ First Department of Internal Medicine and General Medicine, Medical Faculty, Trakia University, \\ Stara Zagora, Bulgaria
}

\begin{abstract}
Demographic trends in the EU-27 show a gradual increase of the 55-64 age group (26\% of the workforce). Natural aging is accompanied by complex age-related changes that lead to a progressive decrease in the body's adaptive capacity. The Work Ability Index (WAI) is a self-assessment tool for the physical and mental resources needed to perform various work activities. PURPOSE of this study was to determine WAI, musculoskeletal disorders and workplace risk factors for the employees of Trakia University, Stara Zagora. METHODS: A survey was performed using the WAI Questionnaire, the Nordic Musculoskeletal Disorders Questionnaire, and a questionnaire on risk factors in the work environment. RESULTS: The total number of valid surveys was 513 (56.5\% of all employees). Workers aged 55-64 had the highest share $-36.6 \%$, followed by those aged $45-54$ years $(24.9 \%)$. The mean WAI score for all employees was good - 41.5. Clinical teaching staff had the highest mean WAI score (43.7), while preclinical tutors (40.9) and medical professionals (40.6) had the lowest. A significant negative correlation was found between WAI and age $(\mathrm{r}=-0.15 ; \mathrm{p}<0.0005)$, as well as between WAI and work experience $(\mathrm{r}=-0.17 ; \mathrm{p}<0.0003)$. Most common in the prevalence of reported diseases were musculoskeletal disorders $(25.0 \%)$, followed by cardiovascular $(14.69 \%)$ and gastrointestinal diseases $(12.7 \%)$. Risk factor analysis showed that $55.9 \%$ of the respondents indicated using display screen equipment, $37.5 \%$ - frequent, repetitive hand movements, and $27.7 \%$ - working at a non-ergonomic workstation for at least half of the working time. CONCLUSION: The obtained results show good work ability of the employees at the university, but also the need for prevention of musculoskeletal disorders, which are mainly due to long work hours involving display screen equipment.
\end{abstract}

Key words: work ability index, musculoskeletal disorders, occupational risk factors

\section{INTRODUCTION}

The Work Ability Index (WAI) is a selfassessment tool of the physical and mental resources needed to perform various work activities. It was first developed in Finland as part of a research project. According to the results of an 11-year long Finnish study WAI showed high predictability for the overall disability and mortality of the studied population (1-3).

The main application of the Index is aimed at early detection of health risks for workers and

\footnotetext{
*Correspondence to: G. Prakova, First Department of Internal Medicine and General Medicine, Medical Faculty, Trakia University, Stara Zagora,Bulgaria, email: gprakova@abv.bg
}

the likelihood of early retirement. The results of the aforementioned survey and the obtained self-assessment of the employees showed their limited ability for the specific work activity in the near future and the necessary measures for maintaining and prolonging work ability. When interpreting results form Work Ability Index surveys account must be taken of the fact that they characterize the current occupation (not the general capacity of the workers) and the corresponding physical and mental requirements for performing the relevant occupational duties. A low WAI score, therefore, does not indicate an individual deficit, but a mismatch between the requirements of the occupation and the working capacity of employees (1). A study of 
WAI in 100 female teachers from secondary schools showed significantly lower work ability compared to a group of 60 office workers, the main cause of which, according to the authors, were the registered musculoskeletal disorders (4).

Musculoskeletal disorders (MSDs) are the most common occupational health issues in the EU countries, affecting millions of workers. MSDs not only affect the health of the individual, but also lead to significant economic and social costs for both employers and society as a whole. In some EU countries, $40 \%$ of paid sick leave benefits are due to MSDs, which represents up to $1.6 \%$ of the country's gross domestic product (5). MSDs reduce the profitability of enterprises and increase social costs for the governments. A report by the United Kingdom Health and Safety Executive (HSE) states that more than 5 000 cases of injuries caused by manual work are registered in the healthcare sector each year. Excessive workload and stress resulting from awkward or static work postures can also lead to health problems (6).

Spinal disorders predominate among MSDs: in the 27 EU countries, around $25 \%$ of workers complain of back pain and $23 \%$ report muscle pain. MSDs are the most common cause for absenteeism, with significantly more (38.9\%) workers being affected in the new Member States (7). Analyzes carried out by the European Foundation for the Improvement of Living and Working Conditions (Eurofound) show that skilled and unskilled workers are equally at risk, that women have a higher risk of upper limb disorders than men, and that older workers complain of MSDs more often. Prolonged standing leads to blood stasis in the lower extremities, strain on the venous system and circulatory disorders, all of which increase the risk of thrombosis significantly. Another consequence of prolonged standing is the increased load on the muscles, tendons and ligaments of the lower limbs. Overloading these anatomical structures can lead to arch collapse and flat feet.

Damage to the musculoskeletal system is often combined with changes in the peripheral nervous system, causing pathomorphological changes at the microvascular level. Fibromyalgia is also associated with widespread musculoskeletal damage, which is characterized as idiopathic, chronic extra- articular pain at a number of sensitive points (8-10). According to Schuring et al. the importance of early retirement among older workers with occupational disabilities is significant (11).

\section{MATERIALS AND METHODS}

The survey was conducted among employees of Trakia University - Stara Zagora in the period October 2018 - May 2019. After obtaining permission from the management of the various university structures, the questionnaires were provided to all employees on paper. The survey included questionnaires for the assessment of the Work Ability Index (WAI), of musculoskeletal symptoms and their characteristics, and a questionnaire on the occupational risk factors for musculoskeletal disorders. The surveys used were approved by the Ethics Commission of the Medical Faculty, Trakia University.

The Work Ability Index questionnaire consisted of seven subcategories related to different aspects of workability: Question 1 compared current work ability with the personal best; Question 2 assessed the ability to work related to the physical and mental requirements in the workplace; Question 3 listed current diseases diagnosed by a physician; Question 4 related to the projected decline in workability due to illness; Question 5 - the number of sick leave days for the past 12 months; Question 6 gave the worker's predicted workability in two years time, and Question 7 assessed the individual's mental resources (12). The total number of WAI respondents was 513, with an average age of 45.1-53.9 years and $16.4 \pm 11.9$ years of work experience.

The study on the location, type and frequency of musculoskeletal complaints was conducted via the Nordic Musculoskeletal Disorders Questionnaire (13), and a questionnaire containing 14 of the most common occupational risk factors for musculoskeletal disorders was used to assess the risk of musculoskeletal damage. These questionnaires were filled out by 542 employees from all structures of the university, with an average age of $49.9 \pm 10.4$ years and 16.7 years of work experience in the higher education. The respondents were grouped and compared by university structures (faculties), gender, age, work experience and main occupations - tutors (pre-clinical and clinical disciplines), 
administration and maintenance, a significance level of $5 \%$, i.e. $\mathrm{p}<0.05$, was accepted for all statistical analyzes, and the statistical software used was StatSoft Statistica v.12.

\section{RESULTS AND DISCUSSION}

In Trakia University - Stara Zagora the relative share of women compared to men is significantly higher $(63.2 \%$ and $36.8 \%$ respectively). This trend is observed in all university structures, and is most predominant for the Medical College ( $87 \%$ women), while least expressed in the Faculty of Veterinary Medicine (51.6\% women). A transversal study of 258 teachers from nine public schools in two municipalities of Sao Paulo aiming to assess their work ability found that most teachers were women with an average age of 41.9 years. The work ability was found good in $42.6 \%$ of respondents, and moderate/ low in $35.3 \%$ (14). A study by Boström et al. among primary teachers found that $81 \%$ of them were women, and the relative share of respondents to the survey was very high - $96.4 \%$ (15). Based on the educational level $37.9 \%$ of all university employees are masters, $36.7 \%$ have a doctoral degree, and $20.1 \%$ bachelors of science. Doctors of science are $2.6 \%$ of all employees. Depending on the position held, $29.4 \%$ of the employees are assistant professors, $18.7 \%$ - associate professors, $10.4 \%$ - professors, $14.8 \%$ - experts/medical specialists, $14.1 \%$ - maintenance workers and $12.7 \%$ - administrative workers. The total number of valid WAI questionnaires was 513 (55.0\% of all surveyed), while the valid MSDs questionnaires were 540 (57.9\%). The highest relative share of respondents for both surveys was observed for the Medical College $(87.5 \%$ and $83.3 \%)$, followed by the Department for Information and In-Service Teachers Training (72.2\% and $77.8 \%$ ), and the Faculty of Economics (71.7\% and 78.3\%). 357 of the WAI questionnaire respondents were women $(69.6 \%)$ and 150 were men $(29.2 \%)$. Six of the respondents did not indicate their gender. The mean age of men and women was $49.5 \pm 9.9$ years and $49.5 \pm 11.6$ years, respectively.

The respondents from the University Hospital and Department for Information and In-Service Teachers Training showed the highest mean WAI score (43.9 and 43.0 respectively), and the Rector's Office the lowest (38.6), followed by the Faculty of Education - 39.4 (Table 1). This result can be to some extent related to the age characteristics of these structures, as the employees in University Hospital (45.1 \pm 12.1$)$ are relatively younger in comparison with workers from the other university structures.

Table 1. Distribution of respondents by university structure, age and WAI.

\begin{tabular}{|l|c|c|c|c|}
\hline \multicolumn{1}{|c|}{ Variable } & $\begin{array}{c}\text { Age } \\
\text { Category }\end{array}$ & $\begin{array}{c}\text { Age } \\
\text { Mean SD }\end{array}$ & $\begin{array}{c}\text { WAI } \\
\text { N }\end{array}$ & $\begin{array}{c}\text { WAI } \\
\text { Mean SD }\end{array}$ \\
\hline Faculty of Agriculture & 65 & $49.3 \pm 10.1$ & 67 & $42.0 \pm 5.4$ \\
\hline $\begin{array}{l}\text { Faculty of Veterinary } \\
\text { Medicine }\end{array}$ & 65 & $46.9 \pm 11.1$ & 67 & $40.1 \pm 6.7$ \\
\hline $\begin{array}{l}\text { Department for Information } \\
\text { and In-Service Teachers } \\
\text { Training }\end{array}$ & 26 & $50.9 \pm 10.3$ & 26 & $43.0 \pm 5.1$ \\
\hline Medical College & 20 & $52.2 \pm 10.2$ & 21 & $41.3 \pm 4.1$ \\
\hline Faculty of Medicine & 139 & $50.6 \pm 10.9$ & 141 & $42.5 \pm 4.6$ \\
\hline Faculty of Education & 21 & $51.5 \pm 7.9$ & 22 & $39.4 \pm 6.2$ \\
\hline Rector's Office & $\mathbf{1 9}$ & $46.1 \pm 9.7$ & $\mathbf{1 9}$ & $\mathbf{3 8 . 6} \pm \mathbf{6 . 1}$ \\
\hline Faculty of Economics & 43 & $46.4 \pm 9.9$ & 43 & $40.8 \pm 5.1$ \\
\hline University Hospital & $\mathbf{3 6}$ & $45.1 \pm 12.1$ & $\mathbf{3 7}$ & $\mathbf{4 3 . 9} \pm \mathbf{3 . 9}$ \\
\hline Haskovo Branch & 17 & $49.2 \pm 8.5$ & 17 & $41.2 \pm 4.6$ \\
\hline $\begin{array}{l}\text { Faculty of Engineering and } \\
\text { Technology - Yambol }\end{array}$ & 51 & $53.9 \pm 7.9$ & 53 & $40.5 \pm 5.5$ \\
\hline
\end{tabular}

v Significantly higher WAI ( $\mathrm{p}<0.05)$ compared to FVM, MC, FEd, FEc, FET

*Significantly lower WAI ( $\mathrm{p}<0.05$ ) compared to FA, DIITT, FM, University Hospital 
According to the European Agency for Safety and Health at Work (EU-OSHA), around 30\% of employed men and women over the age of 45 show a marked decline in their work ability (17).
No significant difference in mean WAI scores was found between men $(41.7 \pm 5.3)$ and women $(41.4 \pm 5.3)$ (Table 2).

Table 2. Work Ability Index by gender, age and length of service.

\begin{tabular}{|c|c|c|c|c|}
\hline $\begin{array}{l}\text { Variable } \\
\text { Category }\end{array}$ & $\mathbf{N}$ & Mean & SD & $* \mathbf{p}<0.05$ \\
\hline \multicolumn{5}{|l|}{ Gender } \\
\hline Men & 150 & 41.7 & 5.3 & \\
\hline Women & 357 & 41.4 & 5.3 & \\
\hline \multicolumn{5}{|l|}{ Age (years) } \\
\hline $25-34$ & 53 & $42.8 *$ & 5.2 & $* \mathrm{p}<0.002$ \\
\hline $35-44$ & 115 & $42.8 * *$ & 4.5 & $* * \mathbf{p}<0.00002$ \\
\hline $45-54$ & 128 & $41.4 * *$ & 5.5 & \\
\hline $55-64$ & 188 & $40.2 *$ & 5.4 & $* \mathbf{p}<\mathbf{0 . 0 5}$ \\
\hline $65+$ & 17 & $44.1 *$ & 4.1 & $* p<0.004$ \\
\hline \multicolumn{5}{|l|}{$\begin{array}{l}\text { Length of service } \\
\text { (years) }\end{array}$} \\
\hline $0-9$ & 169 & $42.1 *$ & 5.0 & \\
\hline $10-19$ & 87 & 41.6 & 4.8 & \\
\hline $20-29$ & 81 & $40.1 *$ & 5.7 & $* \mathrm{p}<0.005$ \\
\hline $30-39$ & 93 & $40.3 *$ & 5.9 & $* * \mathrm{p}<0.010$ \\
\hline $40+$ & 4 & 40.3 & 2.2 & \\
\hline
\end{tabular}

$* * \mathbf{p}<0.028$ between $45-54$ and $35-44$

Similar results for the absence of a gender difference were established by Kavaldzhieva and Dimitrova's assessment of work ability in various occupational groups (16). Based on their age, $36.6 \%$ of the respondents were in the 55-64 year old group, followed by the group between 45 and 54 years $(24.9 \%)$ and those between 35 and 44 years of age (22.4\%). $10.3 \%$ of respondents were in the age range from 25 to 34 years. There was a significantly higher mean WAI score for respondents aged 35 - 45 years $(42.8 \pm 4.5, \mathrm{p}<0.028)$ compared to those aged 45 - 54 years $(41.4 \pm 5.5)$. In a Finnish study only $4 \%$ of teachers aged $45-49$ and $12 \%$ of teachers aged 55-59 had low WAI scores (18).
Regarding work experience, the highest share of respondents fell in the group of to 9 years of service in the university (32.9\%), followed by those with 30-39 years of experience (18.1\%) and $10-19$ years of experience $(16.9 \%)$. The mean WAI score of workers with experience up to 9 years was significantly higher $(42.1 \pm$ 5.0) compared to the groups with 20-29 years $(40.1 \pm 5.7 ; \mathrm{p}<0.005)$ and $30-39$ years of service $(40.3 \pm 5.9 ; \mathrm{p}<0.005)$. A significant and inverse correlation was found between WAI and age $(\mathrm{r}=-0.15 ; \mathrm{p}<0.0005)$ on one hand, and WAI and work experience $(\mathrm{r}=$ $0.17 ; \mathrm{p}<0.0003$ ) on the other (Figure 1).
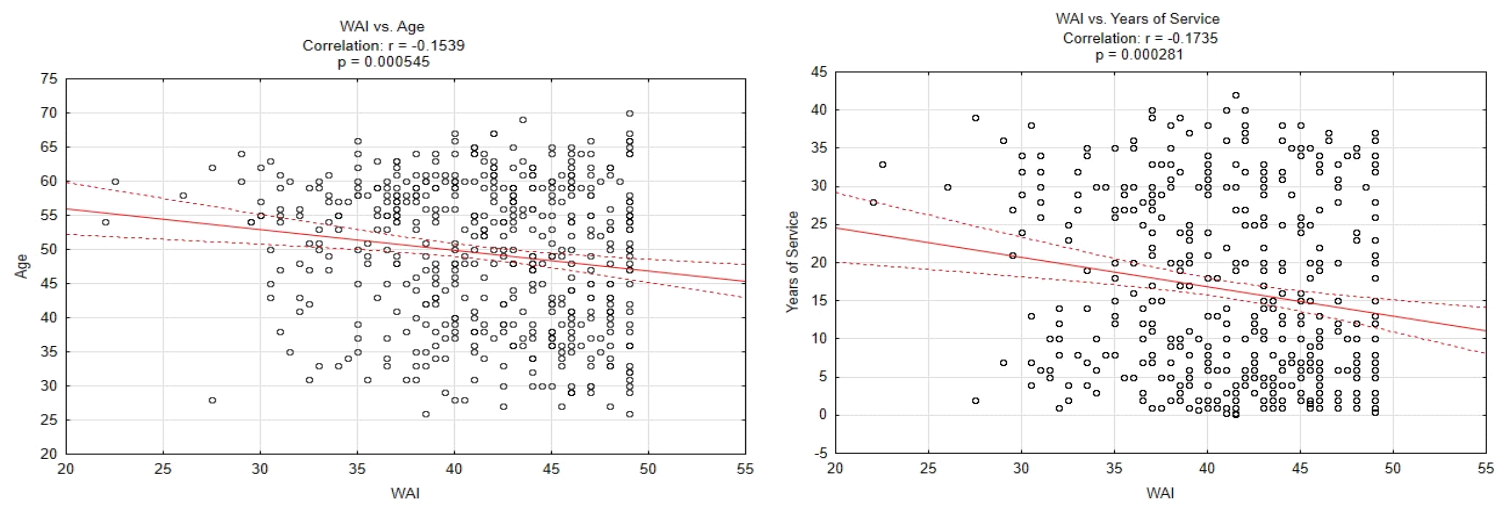

Figure 1. Correlation between Working Ability Index (WAI) and age and length of service. 
While examining some demographic variables in tutors (gender, age, subject and level of teaching), Kinnunen et al. determined that most variations in occupational well-being were due to the subject, and level of teaching. The well-being level was found lowest among teachers of vocational subjects in vocational schools and highest among teachers of special subjects in general education schools. The authors draw attention to the profession and emphasize the need for special attention to the vulnerable teacher groups (18).
Due to the heterogeneous nature of work responsibilities at a university, we divided the respondents according to their profession into the following categories: tutors in preclinical and clinical disciplines, maintenance workers, administrative workers and medical specialists (Table 3). Mean WAI score was significantly higher for clinical tutors (43.7), compared with preclinical tutors (40.9), maintenance (41.7), and medical professionals (40.6), which may be due to the lowest average age of this professional group - 45.1 years.

Table 3. Work Ability Index by occupation and type of work.

\begin{tabular}{|l|r|r|r|r|}
\hline Category & $\mathbf{N}$ & \multicolumn{1}{|c|}{ Mean } & SD & $*$ * $<<0.05$ \\
\hline Preclinical tutors & $\mathbf{2 3 9}$ & $\mathbf{4 0 , 9}$ v & $\mathbf{5 . 5}$ & $\mathbf{p}<0.002$ \\
\hline Clinical tutors & $\mathbf{3 9}$ & $\mathbf{4 3 , 7}$ & $\mathbf{3 , 9}$ & \\
\hline Maintenance & $\mathbf{7 4}$ & $\mathbf{4 1 , 7}$ & $\mathbf{5 , 4}$ & $* \mathbf{p}<0.04$ \\
\hline Administration & $\mathbf{1 1 3}$ & $\mathbf{4 2 . 1} \mathbf{v}$ & $\mathbf{5 , 1}$ & \\
\hline Medical specialists & $\mathbf{1 7}$ & $\mathbf{4 0 , 6}$ & $\mathbf{5 , 4}$ & $* \mathbf{p}<0.01$ \\
\hline $\begin{array}{l}\text { Predominantly mental } \\
\text { work }\end{array}$ & 449 & 41.4 & 5.4 & \\
\hline $\begin{array}{l}\text { Predominantly physical } \\
\text { work }\end{array}$ & 52 & 41.7 & 5.7 & \\
\hline Physical and mental work & 12 & 43.4 & 3.4 & \\
\hline
\end{tabular}

${ }^{*} \mathrm{p}<0.05$ between teachers of clinical, preclinical disciplines, support and medical professionals $\mathbf{v p}<0.05$ between teachers of preclinical disciplines and administration

There was no significant difference in the mean WAI score in the groups based on the nature of work (predominantly physical, predominantly mental, combined mental and physical), but the highest mean WAI score was registered for professions with elements of both physical and mental work (43.4 \pm 3.4$)$, and the lowest values had those exercising mainly mental work $(41.4 \pm 5.4)$. These results confirm the importance of diverse and alternating work tasks for maintaining higher work ability, as well as the negative effect of psychosocial stressors on the work ability of tutors. The relationships between WAI and professional duties have been studied by Schouten et al., who found that office workers had higher WAI scores than manual laborers (19). According to Ilmarinen work ability is lower in the sectors of agriculture and animal husbandry, logging and wood processing, metallurgy, transport, in the social services sector and, in some countries, among teachers as well (17). A study by Vangelova et al. showed that WAI scores of teachers $(37.9 \pm$ 6.0) are a little, but significantly lower ( $F$
$(1,910)=5.195 ; \mathrm{p}=0.023)$ compared to the score of analytical specialists (38.8 \pm 6.3$)(20)$. Our analysis of disease prevalence among the respondents found diseases of the musculoskeletal system on top $(25.0 \%$ of all cases), followed by cardiovascular (14.7\%) and gastrointestinal diseases (12.7\%) - Figure 2.

Work requirements exceeding the capacity of the worker can lead to fatigue, absence from work, and increased incidence of musculoskeletal and mental disorders (14). In our study, we found a high incidence of musculoskeletal complaints. According to Shephard, muscle strength and endurance are individual; usually remaining constant until the age of 40 , after which they decrease slightly in the 40-65 years of age (21), and the average decrease in muscle strength is $10-15 \%$ at the age of 65 years compared to the personal best with significant individual variations between studied subjects

(22). 
SANDEVA G., et al.

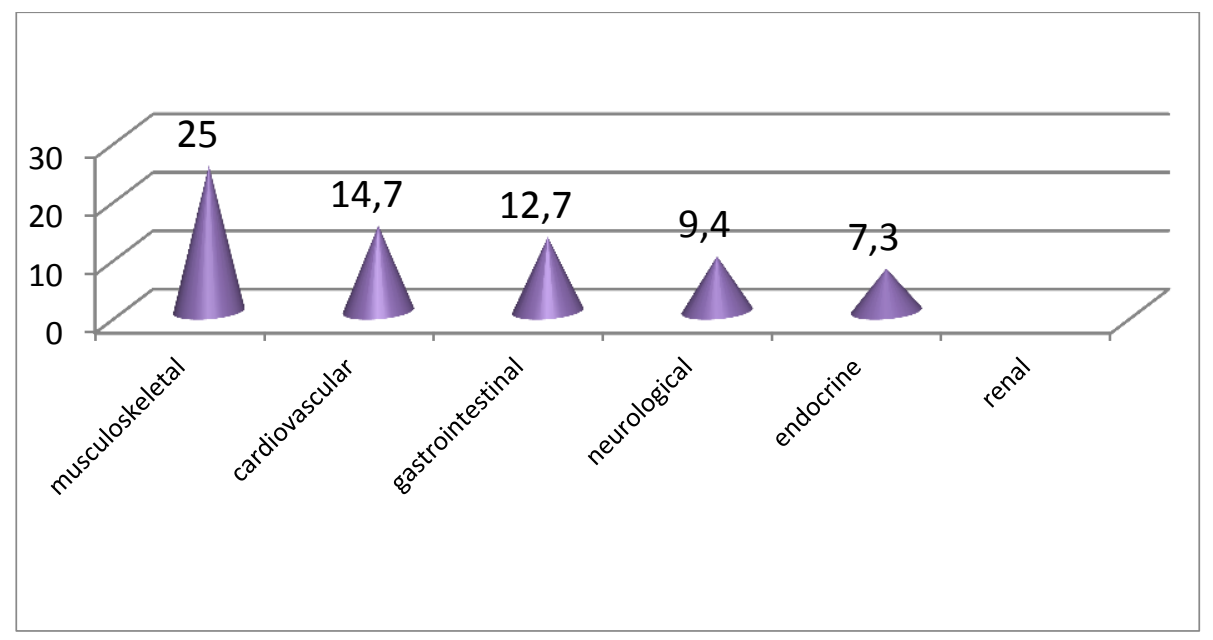

Figure 2. Distribution of the most frequently reported diseases.

Regarding the localization of musculoskeletal complaints from the WAI survey, the most common in the studied population were those of the lumbosacral region (18.9\%), followed by the back $(15.9 \%)$, cervical region $(15.5 \%)$, shoulders (13.7 \%) and knees (11.7\%) (Figure
3). In a study by Seibt et al. among 100 female secondary school teachers and 60 office workers, a lower WAI score was found in the first group, and spinal issues were the most common musculoskeletal disorders in both groups (22).

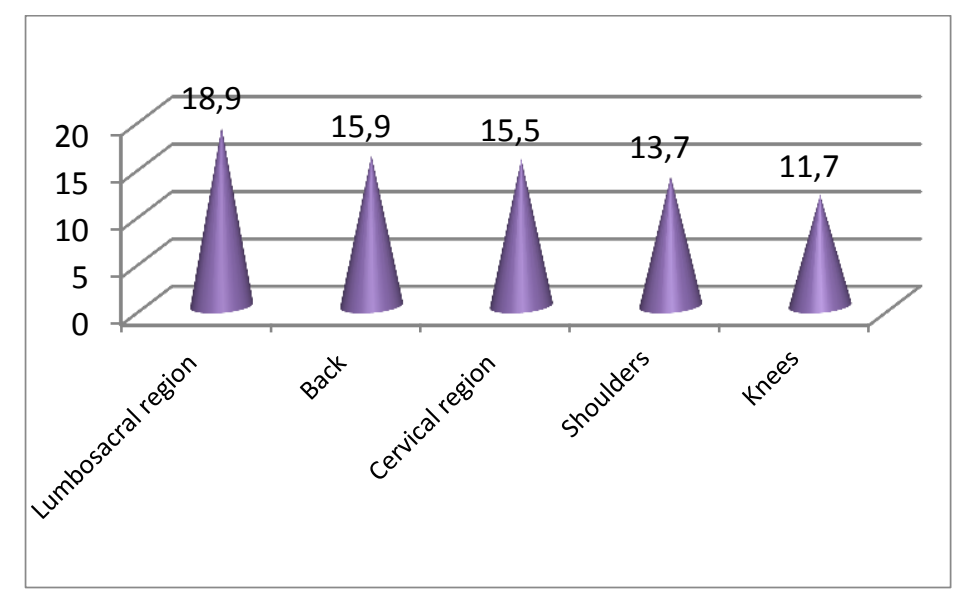

Figure 3. Localization of musculoskeletal complaints in the surveyed employees (\%)

$74 \%$ of the respondents to the Nordic Musculoskeletal Disorders Questionnaire in the university reported one or more complaints of the musculoskeletal system during the last 12 months, the most common being those of the neck, followed by shoulders and upper extremities. The same dynamics were observed in the groups divided by gender, with the addition that in male workers neck disorders were much more common (27.7\% vs. $18.1 \%$ ). Significantly higher average number of complaints was registered in female workers (2.4 musculoskeletal complaints per individual) than in males (1.6), $\mathrm{p}=0.000058$. A higher percentage of musculoskeletal disorders of the hands were found for maintenance workers, as well as disorders of the lower back in administrative staff compared to other occupational groups. A positive correlation was found between the number of reported MSDs and the years of work at the university $(r=0.11 ; p=0.019)$, but not between MSDs and the age of respondents. Risk factor analysis showed that $55.9 \%$ of the respondents indicated using display screen equipment, $37.5 \%$ - frequent, repetitive hand movements, and $27.7 \%$ - working at a nonergonomic workstation for at least half of the working time.

\section{CONCLUSION}

The obtained results showed good overall work ability (WAI) of the employees in Trakia University, but also indicated the need for more effective prevention of musculoskeletal 
disorders, particularly those caused by working with display screen equipment (neck, shoulders, hands, lower back). Further research is needed to identify other occupational factors in higher education that have detrimental effects on work ability, especially psychosocial ones.

The prevention of musculoskeletal disorders of occupational origin requires a comprehensive approach, including the detection, evaluation and control of a number of ergonomic and organizational factors. Such studies in different occupational groups would elucidate the etiological characteristics of these chronic, painful and often permanently disabling diseases.

\section{REFERENCES}

1. Ilmarinen, J., The Work Ability Index (WAI). Occup Med, 57:160, 2007. doi:10.1093/occmed/kqm008

2. Ilmarinen, J., Arbeit alleine erhält die Arbeitsfähigkeit nicht, In: Giesert, M (ed) Arbeitsfähigkeit 2010, DGB Bildungswerk e.V., Dusseldorf, pp 2-11, 2010.

3. Tuomi, K., Ilmarinen, J., Seitsamo, J., Huuhtanen, P., Martikainen, R., Nygard, C., Klockars, W., Summary of the Finnish research project (1981-1992) to promote the health and work ability of aging worker. Scand J Work Environ Health, 23(1):66-71, 1997.

4. Seibt, R., Lutzkendorf, L., Thinschmidt, M., Risk factors and resources of work ability in teachers and office workers. Intern Congress Series, 1280:310-315, 2005.

https://doi.org/10.1016/j.ics.2005.02.006

5. European Agency for Safety and Health at Work, Occupational Musculoskeletal Disorders: Prevention Report, Office for Official Publications of the European Union, Luxembourg, 2008.

6. Health and Safety

Executive,Musculoskeletal injuries in the health and social care sector, 2018. https://www.tuc.org.uk/resource/musculosk eletal-disorders-hse-material-health-andsafety-reps

7. European Foundation for the Improvement of Living and Working Conditions, Fourth European Working Conditions Survey, Office for Official Publications of the European Union, Luxembourg, 2005.

8. Di Franco, M., Iannuccelli, C., Valesini, G., Neuroendocrine immunology of fibromyalgia. Ann NY Acad Sci, 1193:8490, 2010.

9. Wolfe, F., Smythe, H., Yunus, M., Bennett, R., Bombardier, C., Goldenberg, D. et al., The American College of Rheumatology 1990 criteria for the classification of fibromyalgia. Report of the Multicenter Criteria Committee. Arthritis Rheum, 33(2):160-172, 1990.

10.Morf, S., Amann-Vest, B., Forster, A., Franzeck, U., Koppensteiner, R., Uebelhart, D., Sprott, H., Microcirculation abnormalities in patients with fibromyalgia - measured by capillary microscopy and laser flummery. Arthritis Res Ther, 7:R209R216, 2005.

11.Schuring, M., Burdorf, L., Kunst, A., et al., The effects of ill health on entering and maintaining paid employment: evidence in European countries. J Epidemiol Comm Health, 61:597-604, 2007.

12.Tuomi, K., Ilmarinen, J., Jahkola, A., Katajarine, L., Tulkki, A., Work Ability Index. Finnish Institute of Occupational Medicine, Helsinki, 1998.

13.Crawford, J., The Nordic Musculoskeletal Questionnaire. Occup Med, 57:300-301, 2007. doi:10.1093/occmed/kqm03

14. Vedovato, T. \& Monteiro, I., Health conditions and factors related to the work ability of teachers. Ind Health, 52(2):121128 ,

2014. doi https://doi.org/10.2486/indhealth.20130096

15.Boström, M., Björklund, C., Bergström, G., Nybergh, L., Elinder, L., Stigmar, K., et al., Health and work environment among female and male Swedish elementary school teachers - a cross-sectional study. Int $J$ Environ Res Pub Health, 17(1):227, 2020. https://doi.org/10.3390/ijerph170102 27

16.Kavaldzhieva, B. \& Dimitrova, T., Assessment of work capacity in different occupational groups through the working capacity index. Scrip Scien Med, 43(7):7981, 2011.

17.Ilmarinen, J., JIC Ltd, Research Center for Gerontology at the University of Jyväskylä, Finnish Institute for Safety and Health at Work, Promoting the active life of older people in the workplace. 2012, 10.

18.Kinnunen, U., Parkatti, T., Rasku, A., Occupational well-being among aging teachers in Finland. Scand J Educ Res, 38(3-4):315-332, 1994. https://doi.org/10. 
SANDEVA G., et al.

19. Schouten, L., Joling, C., van der Gulden, J., Heymans, M., Bültmann, U., Roelen, C., Screening manual and office workers for risk of long-term sickness absence: cut-off points for the Work Ability Index, Scand $J$ Work Environ Health, 41(1):36-42, 2015. doi:10.5271/sjweh.3465.

20. Vangelova, K., Dimitrova, I., Tsenova, B., Assessment of working capacity of teachers, Bulg J Pub Health, 6 (1): 19-28, 2014.

21. Shephard, R., Age and physical work capacity. Exp Aging Res, 25:331-343, 1999.

22.Seibt, R., Lützkendorf, L., Thinschmidt, M., Risk factors and resources of work ability in teachers and office workers. Intern Congress Series, 1280:310-315, 2005.

https://doi.org/10.1016/j.ics.2005.02.006. 